\title{
EXPERIÊNCIA
}

OAUTOR

Marcos Aurélio Pereira

Assessor de História do Centro Universitário

Positivo, Curitiba/PR.

\section{EDUCAÇÃO PARA OS MEIOS: UM PROJETO COM VÍDEO}

Professor discute linguagem dos meios na sala de aula e elabora o plano para trabalho com vídeo nas aulas de História

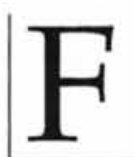

rente às novas demandas sociais, o corpo docente está ensimesmado, procurando identificar sua função e redefinir suas práticas, o que resulta na demarcação de novos limites para o exercício de seu ofício. Todavia, há um consenso: aos profissionais da educação cabe menos o papel de guardiões do conhecimento e mais o de agentes potencializadores das condições essenciais ao indivíduo na historicidade da sua vida pessoal e profissional, levando-o à construção de sua identidade.

Dentre as inúmeras exigências para dar cabal cumprimento a esse papel, destacase a identificação da autofagia na imbricada relação entre realidades e saberes. Não menos importante que esta é o reconhecimento, na elaboração de novos saberes, do desejo da humanidade em dar inteligibilidade a sua vida para, assim, poder atuar de forma consciente, a fim de alçar novos estágios. Esses saberes cons- tituem-se na alavanca reivindicada por Arquimedes para mover o mundo, são seu alfa $(\alpha)$ e ômega $(\Omega)$.

Uma das demandas sociais que, não sendo contemporânea, ganhou destaque a partir do advento da Revolução Industrial é a de levar o aluno a dialogar com os outros seres humanos, quer de seu tempo, quer do passado. Estes últimos são conhecidos por meio de seu legado.

Reconhecer as fontes de erro ou distúrbios, entendidos como o silêncio ou a saturação de informações capazes de obstar a comunicação, é exigência categórica da educação contemporânea. Uma tarefa para a qual os profissionais da comunidade educativa apresentam uma certa limitação.

Decorrente da otimização da comunicação mediante a disponibilização das informações pelos meios de comunicação social numa progressão geométrica, aluno e professor passaram a partilhar a produção simbólica da realidade (temas e problemas), 
constituindo, segundo Guillermo Orozco Gómez ${ }^{1}$, uma comunidade de interesses. Por estar imerso nesta comunidade e dadas as deficiências de formação acadêmi$\mathrm{ca}$, o professor encontra dificuldades em decodificar as linguagens da mídia e, por extensão, em munir o aluno de um histórico mínimo, entendido como o conjunto daqueles conteúdos que permitam o desenvolvimento de habilidades e competências para vir a ser. Noutras palavras, o ritmo de transformações que se operam na sociedade contemporânea, principalmente no último quartel do século XX, acaba por exigir dos profissionais da educação a mesma destreza de Ulisses para transpor a Ilha das Sereias. Poucos são como o herói de Homero, capazes de identificar no canto melífluo da modernidade o fel que a massa está a sorver diuturnamente.

\section{ESTADO ATUAL DA ARTE}

Os meios de comunicação social ou mídia - rádio, televisão e vídeo-também chamados de meios de comunicação de massa, sendo aqui chamados simplesmente por meios, ao serem popularizados ${ }^{2}$, foram incorporados às práticas pedagógicas nestas duas últimas décadas, vindo a constituir-se em seus objetos de estudo e ferramentas para a elaboração de novos saberes. Embora no universo escolar predomine a linguagem escrita, não faltam exemplos deste flerte entre as instituições escolares e os meios, como o rádio, a televisão e o vídeo.
Na utilização do rádio, há experiências ousadas que transpõem os muros da instituição educacional, como a da Escola Municipal João Camargo Ribeiro (Vargem Grande Paulista - SP) e a do programa Roda Pião (Silvânia - GO), citadas pela revista Nova Escola ${ }^{3}$. Outras instituições optaram por projetos intramuros, como o Colégio Positivo Júnior com sua Rádio Estação Positivo (REP) e o Colégio Marista Santa Maria com o programa Perdidos na Manhã (ambos em Curitiba PR). Esses são alguns exemplos que atestam a atração que os meios exercem sobre a comunidade educativa.

Ao se falar do uso da televisão, as experiências têm sido mais modestas. Há uma resistência dos profissionais do ensino básico ao emprego da televisão no processo ensinoaprendizagem. Atribuem a ela o estigma de pasteurizar a cultura.

Posição bastante incômoda e conveniente que serve para revelar a incapacidade do professor em ouvir o canto das sereias, sem ser por ele seduzido. Seu posicionamento, francamente contrário às mensagens veiculadas pela televisão, implica o reconhecimento do impacto da linguagem televisiva sobre a cotidianeidade,

1. OROZCO GÓMEZ, G. Apud CITELLI, Adilson Odair. Meios de comunicaşão e práticas escolares. Comunicação \& Educação. / São Paulo: CCA-ECA-USP/Segmento, n.17, jan./abr. 2000. p.30-36

2. Segundo o Instituto Brasileiro de Geografia e Estatística, de 1995 para 1999, o percentual de residências com televisāo subiu de $81,1 \%$ para $87,7 \%$.

3 RAMALHO. Priscila. Educação oral: aprender a usar o rádio para desenvolver a expressāo, estimular a cidadania e elevar a auto-estima de sua turma. \{on line $\}$ disponível na Internet. (http://www.novaescola.com.br) 2001. 
identificando-a como força impulsionadora das mudanças de comportamento.

Parafraseando Clóvis de Barros Filho, fechando-se às possibilidades educativas da televisão, em particular, e dos meios, em geral, o professor contribui para a erosão do reconhecimento social ao monopólio escolar na produção do conhecimento. A UNESCO, no seu terceiro Grande Programa do Plano a Médio Prazo (19841989), voltado à comunicação, profetizara que as perspectivas abertas pela evolução técnica e pelo aumento do potencial da comunicação possibilitaria uma socialização, cada vez maior, da educação e da cultura. "A comunicação, com seu valor educativo aumentado, cria um novo escopo de educação complementar (...) e tira do sistema educativo o monopólio por muito tempo exercido nesse campo"4.

Essa incapacidade de colocar a televisão a serviço do trabalho pedagógico decorre da limitação dos profissionais da educação em perceber que esse veículo de informação e comunicação não faz uso da linguagem linear e mecânica própria do universo escolar. A televisão emprega uma linguagem antiverbal, descontínua e simultânea. É a moldura de um mosaico. E, segundo o professor José Manuel Morán, sua eficácia "se deve também à capacidade de articulação, de superposição e de combinação de linguagens totalmente diferentes - imagens, falas, música, escrita - com uma narrativa fluida, uma lógica pouco delimitada, gêneros, conteúdos e limites éticos pouco precisos ${ }^{5}$ ".

Não obstante à crítica imputada, outorga-se à televisão uma importância capital na obtenção da informação, por isso, indispensável à comunicação. Que profissional da área de educação já não deu a seus alunos a recomendação para assistir aos telejornais?

De uso bem mais recente, o vídeo tem sido empregado numa intensidade escalar. Contrário ao que ocorreu em relação à televisão, foi recebido como recurso pedagógico por excelência e como sinônimo de modernidade, a ponto de as escolas criarem estúdios ou instalarem videocassetes em cada sala de aula. Sua entrada no espaço escolar foi saudada com grande entusiasmo por alunos e professores. Muitos profissionais do ensino encontraram em sua utilização uma maneira de isentar-se do processo ensino-aprendizagem, transformando a aula numa sessão de cinema e não naquele espaço profícuo para a reflexão mais profunda do significado das informações veiculadas pelos meios. Há ainda os que o utilizam como motivador de uma discussão ou para o fechamento de uma unidade de trabalho. Nas duas situações, o vídeo constitui-se em atrativo e não no objeto de conhecimento.

Rapidamente, a escola passou do livro didático para os jornais, destes para a televisão, depois para o vídeo e, mais recentemente, para a Internet, sem mensurar as implicações na sua manipulação.

4. UNESCO. A comunicaşão a serviço do homem. O correio da UNESCO. Rio de Janeiro 11 (5): 5, maịo. 1983. 5. MORÁN, José Manuel. Mudanças na comunicação pessoal: gerenciamento integrado da comunicação pessoal, social e tecnológica. São Paulo: Paulinas, 1998. p. 159 


\section{DIÁLOGO ENTRE COMUNICAÇÃO E EDUCAÇÃO}

Apesar das resistências e de procedimentos equivocados na organização de uma educação para os meios, restringindo-se na maioria das vezes ao educar pelos meios, o diálogo entre eles e a escola tem sido intermitente, levando o Estado a normatizar a ação pedagógica, no intuito de assegurar, no âmbito da lei, o direito de todos à epistemologia da comunicação ${ }^{6}$.

Ao definir os pontos comuns norteadores dos currículos e de seus conteúdos mínimos, os Parâmetros Curriculares Nacionais indicam para o ensino fundamental, dentre os objetivos elencados, o de levar os alunos a "utilizar diferentes fontes de informação e recursos tecnológicos para adquirir e construir conhecimentos" ". Segundo o mesmo documento, os meios "possibilitam novas formas de ordenação da experiência humana, com múltiplos reflexos, particularmente na cognição e na atuação humana sobre o meio e sobre si mesmo"s e "constituem-se como 'novidades', embora socialmente sejam instrumentos bastante conhecidos e utilizados (exceção feita ao computador, que ainda é algo novo para muitas pessoas) $"$.

Não é diferente a orientação contida nas Diretrizes Curriculares para o Ensino Médio, cujas áreas do conhecimento devem permitir ao aluno "compreender e usar os sistemas simbólicos das diferentes linguagens como meios de organização cognitiva da realidade pela constituição de significados, expressão, comunicação e informação e entender a importância das tecnologias contemporâneas de comunicação e informação para o planejamento, gestão, organização, fortalecimento do trabalho em equipe $^{10}$ ". Essas orientações expressam as demandas da sociedade frente à ascensão dos meios e da indústria da propaganda ${ }^{11}$. Segundo a UNESCO, "as mídias geraram um desequilíbrio no diálogo interno de cada sociedade e criaram uma desigualdade entre a minoria dos que emitem e a maioria dos que recebem. Leitores, ouvintes e espectadores muitas vezes são meros receptores passivos"12.

A incorporação dos meios ao processo ensino-aprendizagem implica seu reconhecimento como educadores ${ }^{13}$, obrigando a instituição educacional a trabalhar na interface da educação com as linguagens da comunicação de massa, procurando educar para os meios, ampliando o grau de inferência que o indivíduo pode exercer sobre as informações e a comunicação. Não obstante as dificuldades, além da hermenêutica, é indispensável conhecer a organização externa dos meios de comunicação de massa, que consiste no funcionamento e no manuseio dos equipamentos.

6. Artigo 32, inciso II, e artigo 36, inciso I, parágrafo $1^{\circ}$. Item II, da Lei Federal 9.394, de 20 de dezembro de 1996. 7. BRASIL. Ministério da Educação. Secretaria de Educação Fundamental. Parâmetros Curriculares Nacionais: terceiro e quarto ciclos do ensino fundamental. Introdução aos parâmetros curriculares nacionais. Brasília: EC/SEF. 1998. p. 56

8. BRASIL. Ministério da Educação. Secretaria... op. cit. p. 135

9. BRASIL. Ministério da Educação. Secretaria... op. cit. p. 142

10. BRASIL. Ministério da Educaçāo. Secretaria de Educaçāo Média e Tecnológica. Parâmetros Curriculares Nacionais: ensino médio. Brasília: MEC/SEMT, 1999, p. 115-116.

11. BACCEGA, Maria Aparecida. Conhecimento, informaçāo e tecnologia. Comunicação \& Educação. São Paulo: CCA-ECA-USP/Moderna, n. 11, jan./abr. de 1998. p. 7.

12. UNESCO. A comunicaşão a serviço do homem. op. cit. p. 6.

13. BACCEGA, Maria Aparecida. op. cit. p. 12. 
Como as duas faces de uma mesma moeda, educar para os meios é assegurar ao indivíduo a condição indispensável para o exercício da cidadania e o domínio da organicidade externa e interna das informações e da comunicação.

Não é possível fechar os olhos às perspectivas abertas pelo avanço das tecnologias da informação e da comunicação, cujas potencialidades educativas não se esgotam. Pelo contrário, sua utilização engendra novas possibilidades de uso. Ao integrar as modernas tecnologias da informação e da comunicação, os profissionais da educação devem, segundo José Manuel Morán ${ }^{14}$ :

1. dominar as formas de comunicação interpessoal;

2. identificar a forma mais adequada de integrar as várias tecnologias, selecionando-as de acordo com os recursos disponibilizados e o público com o qual irá trabalhar;

3. identificar as situações favoráveis ao seu emprego.

\section{VÍDEO EM SALA DE AULA}

Sem se furtar à sua obrigação historicamente definida, que é a de munir o alu- no de um aparelho conceitual, entendido menos como arcabouço teórico e mais como um conjunto de princípios para elaborar o histórico mínimo, a escola deve lançar mão das novas tecnologias de informação e comunicação. Não é possível ensinar as novas gerações com a perspectiva e os conceitos estabelecidos para uma outra época, quando os seres humanos eram outros, assim como suas necessidades e a leitura de mundo.

Partindo dessas considerações, o profissional do ensino da História, preocupado com a otimização do diálogo entre educação/meios, pode empregar a filmadora e o videocassete na construção de um vídeo documentário ${ }^{15}$, permitindo ao aluno organizar e expressar informações históricas de um dado período através da linguagem fílmica. A experiência mostra que, na execução do projeto, o ideal é desenvolvê-lo nas aulas de Históriạ, durante 16 horas/aulas.

Para melhor visualização do tempo mínimo necessário e das fases do trabalho, segue o cronograma de atividades proposto aos alunos das oitavas séries.

\section{CONSTRUINDO O VÍDEO- HISTÓRIA}

Na produção de um vídeo-história, pode-se dividir o trabalho em quatro fases, em que os conteúdos específicos da história serão explorados ao lado daqueles pertinentes aos das tecnologias de informação e comunicação de massas.

14. MORÁN, José Manuel. Ensino e aprendizagem inovadores com tecnologias. Disponível na Internet. <http:// www.eca.usp.br/prof/moran/interne.htm> 2001.

15. O projeto foi desenvolvido pela área de História do Colégio Marista Santa Maria, entre 1996 e 2000, e Colégio Positivo Júnior em 2001. Ambos em Curitiba - PR. 


\begin{tabular}{|c|c|c|}
\hline Fase & Aula & Atividade \\
\hline \multirow{6}{*}{12.} & $1^{2}$. & $\begin{array}{l}\text { Definir o tema a ser trabalhado e orientar a leitura do texto básico (livro didático) e de textos } \\
\text { complementares (outros livros, documentários, periódicos, entre outras fontes). }\end{array}$ \\
\hline & $2^{*}$. & Em grupos, segundo roteiro previamente fornecido, discutir o texto básico. \\
\hline & 34. & Com toda a turma ou em pequenos grupos, elaborar uma síntese, tendo em vista o tema escolhido. \\
\hline & $4^{4}$. & Ler e discutir a síntese, procurando corrigir possíveis erros de conteúdo. \\
\hline & 5*. & Definir o formato do vídeo-história - documentário, dramatização, telejornalismo, entre outras. \\
\hline & $6^{n}$. & Elaborar o roteiro em pequenos grupos. \\
\hline \multirow[t]{4}{*}{$2 *$} & $7 *$ & Definir qual dos roteiros será utilizado para a filmagem. \\
\hline & $8^{*}$. & Selecionar a iconografia a ser empregada nas filmagens. \\
\hline & 94. & Selecionar as músicas a serem utilizadas na ediçāo. \\
\hline & $10^{4}$. & Apresentar e discutir a linguagem do cinema e do vídeo ${ }^{16}$. \\
\hline \multirow[t]{4}{*}{$3^{4}$. } & $11^{*}$. & $\begin{array}{l}\text { Ensinar o manuseio da filmadora e das técnicas de filmagem (enquadramento, luz e posicionamento } \\
\text { da câmera). }\end{array}$ \\
\hline & $12^{*}$. & Filmagem. \\
\hline & $13^{*}$. & Filmagem. \\
\hline & $14^{*}$. & Edição. \\
\hline \multirow[t]{2}{*}{$4^{4}}$. & $15^{\mathrm{a}}$. & Ediçāo. \\
\hline & $16^{\circ}$. & Edição. \\
\hline
\end{tabular}

$1^{a}$. Fase - Produção dos saberes

Através do livro didático e de outras fontes escritas, os alunos irão apropriar-se dos dados mínimos necessários à produção de um conhecimento acerca da realidade histórica. É a fase em que o professor atuará como agente motivador da pesquisa e "parteiro das idéias". É o momento em que ele lançará questões, levando os alunos a utilizar as informações disponibilizadas pelos meios tradicionais de informação e comunicação na elaboração de novos saberes. Assim, professor e alunos definem o modelo a ser empregado na apresentação dos referidos saberes em um programa de vídeo.

$2^{\mathrm{a}}$. Fase-Roteiro

A elaboração do roteiro assegura uma boa produção fílmica. Afinal, para que as pessoas tenham prazer em assistir a um filme ou programa televisivo, entre outros elementos, é necessário o registro escrito de todas as cenas, definindo-se os gestos, as expressões, as situações e tudo o que será dito. Na sua elaboração, o aluno estará reelaborando os dados apresentados no material didático e em outros veículos de informação e comunicação. Por se tratar de um projeto educativo, é recomendável a elaboração de roteiro identificando apenas as falas principais e as imagens a serem apresentadas.

Em seu livro Ver e ouvir ${ }^{7}$, o roteirista Aloysio Niemeyer Filho, referindo-se ao roteiro para vídeo, afirma não ser necessário "aquela coisa escrita de maneira formal, em blocos de cena". Afinal, a 'lin- 
guagem de vídeo é cômoda, versátil e fácil de trabalhar.'

A escrita do roteiro possibilita uma melhor distribuição de tarefas entre os alunos, permitindo ao professor verificar as conexões que cada um conseguiu fazer entre aquelas informações apresentadas pelo livro didático e outras fontes escritas com a iconografia e com o acervo musical.

\section{$3^{\mathrm{a}}$. fase - Gravação}

Para produzir um bom vídeo, é preciso mais do que uma câmera na mão e uma idéia na cabeça. Faz-se necessário dominar as técnicas de gravação ou filmagem. Os iniciantes no trabalho com a produção de um vídeo devem estar atentos ao enquadramento, ao uso dos planos e à posição e ao movimento da câmera.

Mediante o ensino destas técnicas, o aluno terá acesso à gramática do cinema e da televisão, aprendendo a decodificar

Resumo: $\mathrm{O}$ artigo discute a apropriação pela escola das linguagens das tecnologias de informação e da comunicação, principalmente as dos meios de comunicação de massa. Defende que o professor deve trazer para sua aula os recursos audiovisuais, utilizando-os não apenas como elementos ilustrativos, mas como portadores de um saber que deve ser analisado, criticado, reconstruído e incorporado como linguagem além da escrita. Apresenta ainda uma experiência com o vídeo nas aulas de História.

Palavras-chave: meios de comunicação, vídeo-histórico, professor, escola a linguagem empregada na produção cinematográfica e televisiva.

$4^{a}$. Fase - Edição

Segundo Aloysio Niemeyer Filho, editar um filme é tirar de uma fita bruta as cenas indesejáveis, selecionar as desejáveis e juntar tudo de acordo com um roteiro pré-estabelecido em um produto final coerente e significativo.

$\mathrm{Na}$ organização de uma ilha de edição doméstica, fazem-se necessário dois videocassetes, dois televisores, um microfone, um aparelho de som e um mixer.

\section{PARA CONCLUIR}

A escola deve redefinir seus currículos e as estratégias que favoreçam a elaboração daquele mínimo histórico, permitindo ao aluno ocupar e construir seu espaço em seu próprio tempo, lançando mão das tecnologias disponibilizadas.

(Education for the media: a project with videos) Abstract: The article discusses the appropriation, by the school, of the information and communication technology languages, most especially those of the means of mass communications. It defends the idea that teachers must take audiovisual resources to the classroom, not only using them as illustrative elements, rather, as the bearers of a type of knowledge that must be analyzed, criticized, reconstructed, and incorporated as a language that is beyond writing. It also presents an experience with videos in History classes.

Key words: means of mass communication, history video, teacher, school 